\title{
Die Entwiffluthy
}

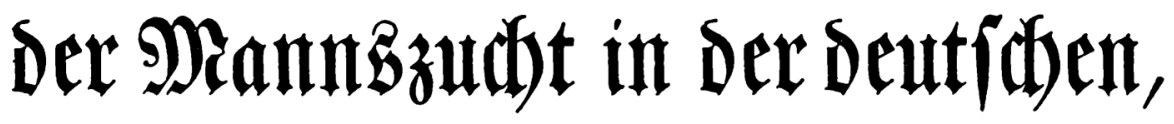

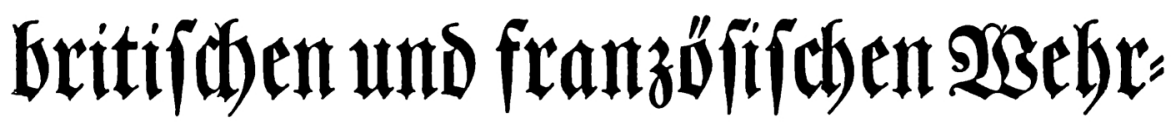 madet jérit 1914}

\author{
$\mathfrak{B o n}$ \\ Dr. (Erid) Sdwininge \\ Profeffor an ber Univerfitåt $\mathfrak{B}$ ien
}

1940

S. Sdweikger $\mathfrak{B e r l a g}, \mathfrak{B e r l i n}$ und $\mathfrak{R u ̈ n d e n}$ 
Drud bon Dr. F. \$. Datteret \& Ele., frreifing=\$MUnder. 
Herrn Ministerialdirektor

Dr. Rudolf Lehmann

Chef der Rechtsabteilung im Oberkommando

der Wehrmacht

in Verehrung

gewidmet 
